\title{
EL DELIRIO EN SOLEDAD. ANÁLISIS DEL DRAMA DEL PALACIO DESHABITADO DE RAMÓN GÓMEZ DE LA SERNA.
}

\author{
Carmen Marimón Llorca*
}

\begin{abstract}
RESUMEN. En este artículo abordo el estudio del Drama del Palacio Deshabitado (1909) de Ramón Gómez de la Serna. Utilizo como instrumento de análisis el método de Tordera en el que se incluye el sistema de trece signos de Kowzan más la dimensión simbólica del texto. La especialísima naturaleza de esta obra teatral -cuyo contexto estudiamos al principio con cierto detalle- requería un método de estudio que prestase atención a todo lo que puede resultar significante en una representación teatral. El análisis descubre finalmente que lejos de encontrarnos ante un episodio singular en la trayectoria literaria de Ramón, su teatro, y esta obra en concreto reúnen muchas de las inquietudes personales (erotismo, muerte, verdad) y los referentes culturales (modernismo, vanguardias) que vertebran la totalidad de su producción.
\end{abstract}

ABSTRACT. Along this work I deal with the study of Ramón Gómez de la Serna's Drama del Palacio Deshabitado (1909). For this purpose, I have chosen Tordera's method that includes the Kowzan system of thirteen signs and a study of the symbolic dimension of the play. The singularity of the Drama -whose literary context is quite exhaustively analysed at the beginning of this essay-required a method that regarded any significant element in the performance of the play. The analysis finally proposes that we are not facing an odd episode in the literary trajectory of Ramón; on the contrary, his theatre -and this play in particular-bears many personal worries (erotism, death, truth) and cultural references (modernism, avant-garde) that characterizes his whole production.

El mundo literario de Ramón Gómez de la Serna está poblado de toda suerte de personajes. Su extraordinaria fecundidad como escritor y la extravagancia prodigiosa de su imaginación convierte todo lo que escribe en un objeto singular c irrepetible. Para Ramón escribir fue algo congénito, innato, que afluyó tan temprano como tantas otras

•Licenciada en Filología Hispánica por la Universidad de Alicante. 
inquietudes que le llevarían a tomar desde muy pronto, una actitud personal ante la vida. Niño prodigio de las letras -a los dieciséis años había escrito su primera obra !autobiográfica! y a los veinte dirigía la revista de su padre, Prometeo-, también fue, paralelamente, un niño precoz en las relaciones amorosas. Siendo aún adolescente, en 1908, conoce a Carmen de Burgos, intelectual respetada y mujer liberada de su tiempo bastante mayor que él. La intensidad y, una vez más, la particularidad de sus relaciones, debieron contribuir a avivar en Ramón las inquietudes sexuales de un adolescente apenas estrenado. Sus primeras obras -y entre ellas su teatro- están impregnadas por una profunda preocupación por las relaciones hombre-mujer, por las posibilidades y la certeza del amor, por las verdaderas oportunidades que ofrece la sociedad para que ćste sea fecundo y auténtico. Pero no nos engañemos, la obsesión sexual-amorosa de Ramón en sus primeros tiempos no es un fenómeno aislado. La primera etapa de la vida literaria de Ramón, lo que Umbral ha llamado la "prehistoria literaria de Ramón" (Umbral 1978:46) está caracterizada precisamente por la rebeldía. Durantc los años de Prometeo (1908-12) y quizá un poco antes y un poco después, Ramón se rclaciona con la intelectualidad modernista más radical, hombres en los que se mezclan "nictzchenianismo, anticlericalismo, pansexualismo y toda una mitología subversiva".

Las primeras obras de Ramón están llenas de todo eso también. Durante estos primeros años Ramón recoge, asimila y transforma según las necesidades de su mundo particular. Ramón es un iconoclasta, quiere romper, destruir, desmitificar, arrancar de cuajo la literatura y el mundo de manos de la estrechez burguesa. Su padre, liberal seguidor de Canalejas, hombre mezclado en ideologías más o menos radicales debió contribuir, al menos, en darle a Ramón la oportunidad de expresar sin cortapisas su pensamiento. Durante los años de su juventud Ramón es un rebelde: "es un joven...enmelenado, fumador de pipa, tocado con un chambergo blando y bufanda a cuadros, es su continente de los que inquietan a los policías" (Granjel 1962:26). Es un anarquista, a su manera, pero lo es, un anarquista, a su airc -como todo en él- y, su literatura prehistórica, la manifestación más acabada de su irreverencia.

Porque Ramón, literariamente hablando, tenía contra qué rebelarse. Dice Umbral:

"La rebelión inicial de Ramón y su anarquismo literario se justifican en principio como lucha contra el realismo decimonónico que domina España: Galdós en la novcla y Benavente en cl teatro" (57).

En 1909, Ramón pronuncia un discurso en el Ateneo de Madrid: "El concepto de la nueva literatura", es un manifiesto escandaloso, en cl que propugna una nueva literatura basada en la vida, atrevida, liberada de lo normal; reniega del concepto histórico de la literatura y aboga por una nueva que "revive las inquietudes embotadas, traspasando todas las prohibiciones" (Camón Aznar 1972:103). Los años de Prometeo están llenos de los contactos con las nuevas corrientes artístico litcrarias de la ćpoca; su viaje a París, sus contactos con Marinetti hacen de él un abanderado de la vanguardia europea con la que coincide personal e idelógicamente y con la que confluirá a lo largo de su vida sin militar nunca en otra cosa que no fuera su propia revolución: el ramonismo. 
Durante los primeros años de su carrera literaria, Ramón se preocupa por el teatro. Comprometido literariamente con cualquier tipo de aire renovador, decide montarse en el tren de la renovación teatral que por aquellos años tenía lugar en España. Su participación consistió no sólo en escribir con fruición obras dramáticas -entre 1909 y 1912 escribio 17 obras de teatro- sino en llegar a ser vicepresidente del teatro de Ensayo, fundado en 1910 bajo los auspicios de Benavente.

Los problemas del teatro español no nacieron con el siglo ni se terminaron en los primeros años, muy al contrario voces de protesta contra la monotonía y el escaso nivel de la escena española venían alzándose en los periódicos y las revistas especializadas desde la última década del siglo y llegarán a su punto culminante en los años 25-30 (Dougherty 1984:93). En los años en que Ramón escribe su teatro triunfa el teatro burgués. En 1904 Arniches estrena su sainete Las estrellas; en 1907 Benavente triunfa con Los intereses creados y Señora ama, un drama rural; 1909 y 1910 verán cl éxito de Eduardo Marquina y el teatro poético, los éxitos serán Las hijas del Cid y En Flandes de ha puesto el sol. Ese mismo año Muñoz Seca estrenará El verdugo de Sevilla. Los Quintero repiten éxito con Malvaloca en 1912 (en 1908 ya fueron bien recibidos con Los de Caín). Linares Rivas estrena en 1914 La fuerza del mal y 1916 verá en escena lo mejor de Amiches; La señorita de Trevelez. Estos son los autores que monopolizarán los estrenos, las compañías sólo quieren representarlos a ellos, los empresarios saben que tienen el éxito asegurado y el público se complace una y otra vez: llora en los dramas, ríe a carcajadas en las comedias y sainetes y se emociona sobrecogido ante los dramas históricos del teatro poético. Todo estaba hecho a la medida de su gusto. Si a esto unimos la complicidad de cierta crítica, estamos ante una red de intereses que difícilmente podía derrumbarse; porque, en realidad, ¿quién quería derrumbarlo?, locierto es que se trataba de un grupo de intelectuales que en ocasiones eran al mismo tiempo críticos, autores y público potencial, una minoría que se irá agrandando al transcurrir de la década pero que en los años 10 todavía era débil. No hay que olvidar que el teatro era sin duda el fenómeno social de mayor importancia en el país y que a pesar de sus lastres, se encontraba en pleno apogeo. Solo en Madrid se contabilizan en 1909 treinta teatros abiertos y 411 estrenos (Díez Borque 1988:631).

Los verdaderos problemas del teatro español eran económicos y estructurales. La falta de intervención pública convierte a los empresarios en negociantes, cuya única preocupación es ganar dinero, para lo cual deben asegurarse el lleno cuando levantan el telón. La mejor garantía era estrenar nuevas obras de los mismos autores; éstos eran sometidos a una excesiva presión comercial que irremediablemente repercutía en la calidad de sus obras (Dougherty 1984:98). Los actores, por su parte, eran parte de la maquinaria del éxito y querían protagonismo, hasta el punto que muchas veces las obras se escribían en función de tal o cual actor o actiz. La mayoría de la crítica veía todo esto con complacencia, sólo algunas voces aisladas, como la de Ramóm y posteriormente y de forma más sistemática la de Ortega y Gasset, claman por un cambio sustancial en la concepción del hecho teatral que pasa sin duda por la intervención pública. Habrá que esperar a la República para advertir una nueva actitud institucional ante el teatro. Para entonces además, el cine comenzará a rivalizar con las representaciones teatrales y, en 
adelante, otros muy distintos van a ser los problemas que acucien al siempre en estado crítico teatro español. Pero en aquel momento era necesario militar en la causa y Ramón lo hizo.

El teatro sirvió además a Ramón para dar salida a sus inquietudes internas, sus obras son reflexiones sobre sí mismo, diálogos con su propio yo. Dice Ramón:

"Mis dramas y mis comedias han sido arrebatos de mi adolescencia, maneras de no estar solo con mis deseos de un arte arbitrario /.../ Con el murmullo de mis producciones teatrales se calmaba algo mi anhelo antiteatral". (Granjel 1962:162)

Muchos años después, desde su madurez literaria, Ramón renegará de su producción teatral y no tendrá pudor alguno en eliminarla de sus obras completas. Así habla de ella en Automoribundia:

"¿Qué yo tuve una época de escritor de teatro y los primeros tomos que publiqué fueron de teatro? Sí, es verdad, pero fue un teatro muerto, teatro para leer en la tumba fría, y recuerdo esa época como si hubiesen hablado conmigo las malas musas teatrales." (Granjel 1962:163)

Este desprecio de Ramón a su propia obra dramática, el hecho de que nunca se representaran sus obras de juventud y la enormidad en cantidad y calidad de su obra posterior, han provocado el silencio y la indiferencia de la crítica que poco o nada dedica al estudio de sus dramas. Afortunadamente este vacío se empieza a llenar con la aparición del librito de Marta Palenque, El teatro de Gómez de la Serna: estética de una crisis en 1992. En él por primera vez encontramos un breve pero detallado estudio sobre el teatro de Ramón cuyo máximo mérito, a mi juicio, es el de situar su teatro en las coordenadas estéticas e ideológicas de la época, así constatamos que si Ramón se debe mucho a sí mismo, también -como nos muestra la autora y como referimos más arribasu obra está llena de su tiempo. En la base de su pensamiento, vitalismo nietzschiano y nihilismo procedente del concepto del absurdo de la existencia, colocan a la muerte como referente central de sus obras (Palenque 1992:21). Estéticamente encontramos una singular síntesis en sus obras de los más acabados logros modernistas (sensualismo, misticismo, simbolismo) y las primeras manifestaciones vanguardistas (dadá, expresionismo, cubismo). El resultado es un teatro sorprendentc, justificablc histórico-literariamente, pero irremediablemente abocado a la incomprensión y al fracaso cuando no al olvido y al rechazo. En nuestro análisis del Drama del palacio deshabitado comprobaremos cómo se cumplen la mayoría de estos presupuestos: exquisitas acotaciones, ambientes cargado de sensualidad con diálogos entrecortados y la mucrte como motivo central.

Pocos críticos hasta ahora han prestado atención al teatro de Ramón, sólo en estudios generales de la obra se menciona el teatro dentro del "saco" de obras de juventud. La mayoría de estas menciones se limitan a repetir opiniones ajenas o a contar 
el argumento de las obras; sólo algunos críticos como Camón Aznar y Granjel se han detenido algo más en el análisis. Granjel clasifica la obra dramática ramoniana en base a los dos temas fundamentales que la atraviesan: el problema erótico y la crítica social; pocas veces, sin embargo, las obras pertenecen radicalmente a uno u otro grupo. Este es el caso del Drama del palacio deshabitado (1909) en el que -como veremos en el análisis de la significación de la obra- si bien es una fuerte rebeldía contra los convencionalismos sociales lo que subyace a toda la obra, la reivindicación de una vida erótica sin presiones es lo que, en definitiva, mueve a todos los personajes.

Antes de entrar en el análisis concreto de una de sus obras debemos tener en cuenta:

- que la obra teatral de Ramón no es un hecho aislado dentro de su obra completa y su biografía; coincide cronológicamente con la publicación de Morbideces (1908) -lleno de decadentismo simbolista- y con sus primeros contactos con Paris y con la vanguardia futurista, especialmente con Marinetti, cuyos manifiestos publica en Prometeo a partir de 1910.

- que fue el propio Ramón el que queriendo limar su rebeldía desde posturas más conservadoras, excluye su teatro de las obras completas, pero ésto sólo se explica dentro de la personalidad y la obra ramoniana, cuyo máximo hallazgo, la greguería, es el resultado final de la búsqueda de la verdad a través del absurdo que marcó toda su producción. El Ramón decadente, el futurista, el ultraísta se superponen sin excluirse y producen una obra con múltiples caras que su teatro juvenil y sus dos dramas posteriores anuncian.

- Por otra parte, el intento renovador de Ramón se enmarca igualmente -como hemos visto más arriba- en el movimiento generalizado de los intelectuales para buscar una salida a la situación de mediocridad y vulgaridad que caracterizaba el teatro español de los primeros años del siglo. Ramón y Ortega, por un lado, con sus manifiestos; Ramón otra vez y Valle-Inclán y Azorín y Unamuno con sus obras, por otro, lo intentarán, pero la confabulación de empresarios, actores, autores y público burgués será una potente máquinaria que acabará con las pretensiones de jóvenes autores y críticos inconformistas.

Me aventuro ahora a analizar con cierto detalle una obra de teatro de Ramón Gómez de la Serna. Mi elección fue El drama del palacio deshabitado y el método de análisis el que propone Tordera (Talens 1978:157-199). El método de Tordera me pareció, sin duda, el más ajustado a las necesidades de la obra elegida, porque cubre un gran abanico de campos (sintácticos, semánticos, linguiísticos, no lingüísticos) que son imprescindibles para interpretar la poco convencional obra de Ramón. Me parecieron especialmente apropiados dos aspectos: que incluyera el análisis de los signos de Kowzan que, dada la riqueza de las acotaciones y la precisión escénica de Ramón, son excepcionalmente clarificadores; y por otro lado, que diera la oportunidad de la interpretación de los símbolos como dimensión significadora de la obra. Si sintácticamente, como veremos, la obra reviste cierta complejidad, es el campo significativo en el que es necesario encontrar instrumentos analítico-orientadores que guícn la posible interpretación de la 
obra a través de las relaciones entre los distintos campos de significación. Sin más preámbulos paso al análisis de El drama del palacio deshabitado.

\section{DIMENSIÓN SINTÁCTICA}

Vamos a enfrentarnos a este apartado utilizando la propuesta de Kowzan de trece sistemas de signos cuyas relaciones dan a la obra el armazón estructural sobre la que ésta se sostiene.

\section{La palabra}

$\mathrm{Si}$, al igual que A. Tordera, entendemos por palabra el análisis de la obra en tanto que texto literario, es decir, el análisis de los signos lingüisticos de la obra, será imprescindible hacer una descripción de las situaciones dramáticas que le dan coherencia y sentido como texto dramático.

La obra está compuesta por un único acto a lo largo del cual distintos personajes entran y salen de escena sin ningún motivo aparente, excepto que todos comparten el mismo espacio. Atendiendo a estas entradas y salidas la obra podría dividirse en diecisiete escenas. Sin embargo, no resulta esclarecedor ni significativo su enumeración estadística. La mayoría de ellas se refieren al paso de un personaje por escena -de un lado al otro del escenario- sin que se establezca relación con los otros personajes que allí se encuentran. Así las escenas 1 a 5 se podrian reducir a una única situación dramática que podríamos definir como diálogo D. Dámaso-D. Pedrín que queda interrumpido dos veces por las entradas y salidas de Gloria la Profesa y el ayuda de Cámara. La escena 6 supone la incorporación de un nuevo personaje, el Bastardo, a la conversación con lo que se añade un elemento más al núcleo inicial. Las escenas 7-11 se caracterizan por la presencia de los marqueses, los condes y el bufón que entablarán relaciones con el núcleo inicial y con Sara, personaje nuevo que pasará en un momento por escena. Cuando éstos desaparecen la obra corre hacia su final. En las escenas 12-15 se incorporan progresivamente Gloria la Profesa, Leticia y el bufón, y planean irse al jardín. En la escena 15 se produce el primer movimiento escénico intencionado de la obra: el bufón va a por el resto de los personajes y juntos hacen un corro en dirección al jardín. Las escenas 16-17 son de vital importancia: Rosa, un personaje vivo, entra, busca a su amado, Juan, que entra por la ventana y comienzan a hacer el amor. D. Dámaso y Leticia deciden irse al jardín.

Después de este repaso sólo hay una conclusión posible. La obra no está concebida en torno a la acción de los personajes porque ésta como tal no existe. Si hay algunos elementos estructuradores de la obra ésos son: 1. La existencia de un doble espacio, uno en el que ocurren los hechos y otro, temido, deseado, al que los personajes quieren y no quieren ir al mismo tiempo. 2. La existencia de una doble referencia temporal, el pasado y el presente, cuya dialéctica provoca esos mínimos estructurales que hemos descrito anteriormente.

Para algunos autores, la falta de auténtica acción en las obras de Ramón se debe a 
que no quiso someterse a las leyes del teatro (Ponce 1968:124). En este caso creo que podriamos hablar en otro sentido: los personajes de la obra son personajes muertos que hablan de la posibilidad de sus vidas pretéritas, si nada les movía en vida ¿qué razón tienen ahora después de muertos para moverse, para hacer algo?. En contraste con ellos están Rosa y Juan, los vivos; si nos damos cuenta, su presencia es la única presencia activa de toda la obra: entran, se llaman, se buscan, se hablan, se abrazan, se mueven, se aman. Estoy saliéndome de lo puramente sintáctico y adelantando información que pertenece a otros apartados, pero creo que es necesario para justificar que, tal vez, la noacción, el no pasar nada es un acto voluntario por parte de Ramón para poderlo contrastar con la repentina actividad que se pone en marcha con la entrada de los vivos. Podemos concluir, pues, que el auténtico estructurador de la obra, el cje que le da sentido es la dialéctica simbólico-sintáctica entre lo que son y lo que representan los personajes en relación con un espacio y un tiempo bien definidos también a nivel simbólico, que sólo cobrarán sentido con el entrecruzamiento de los planos vivo-muerto que se produce al final de la obra.

\section{Tono}

Hay numerosas indicaciones referidas al tono en que los personajes pronuncian sus palabras, pero la mayoría de estas indicaciones -que se encuentran en su totalidad en las acotaciones- son polisignificativas. No sólo determinan la forma de dicción de la frase - la palabra, sino también el sistema de signos mímica-gestos, indiscutiblemente unidos en este caso a la emisión de sonidos. Una acotación como "aterrorizada" o "autoritario" exigen no sólo una cierta inflexión de voz, sino una mímica facial concreta y, probablemente, un movimiento de todo el cuerpo adecuado. Aunque no ocurre con todos los personajes, hay algunos para los que las indicaciones de tono mantienen cierta regularidad. Así el bufón habla: "altisonante", "autoritario", "asombrado", "amoroso", "gritando", "campanudo", "con fanfarronería". D. Pedrín y D. Dámaso suelen hablar "con toda sutilidad, parsimoniosamente", "a media voz"... Aparte de estas indicaciones particulares, la acotación inicial de la obra da las pautas generales de cómo debe ser el tono de sus emisores: "hablan sin gestos, como ventrílocuos, pero sacando la voz de otro sitio que no es el vientre, de su sombra..." El tono inicialmente parece contribuir a la falta de motivación y de movimiento que impregna el sentido de la obra.

\section{Mímica-Gestos}

La acotación que encabeza la obra y de la que acabamos de citar un fragmento nos dice mucho sobre lo que nos vamos a encontrar en ella:

Tienen una mirada macilenta, empalidecida, muerta/.../Tienen ademanes delicados, nebulosos, quietos, convincentes, de una matématica precisión /.../ sin perder en suavidad y en temperancia ... Son sumamente flexibles. Hablan sin gestos... 
El resto de las acotaciones referidas a los gestos -que abundan- son las que hacen referencia a la descripción de aquel gesto que caracterizará al personaje. Así Gloria la Profesa lleva "las manos cruzadas en actitud cuitada", los nobles hacen "gestos antiguos e importantes", D. Dámaso y D. Pedrín están repanchingados en sus butacones". El Silencioso "tiene un gesto y un ademán colmado de saciedad y munificiencia"... Además se indican las variaciones en esta actitud general. Como vemos los gestos están perfectamente conectados con el tono que a cada personaje y a la obra en general le corresponde. La mayoría de ellos sirven para acompañar a la palabra y por tanto muchas veces contribuyen a intensificar algo sentido por los personajes, a definir un movimiento -en este caso estaría conectado con el próximo sistema de signos del que es muy díficil separarlo.

\section{Movimiento}

En una obra en donde apenas hay acción, el movimicnto escénico de los personajes resulta extremadamente importante. Ya no son sólo las entradas y salidas, sino la forma misma de desplazamiento y la carga comunicativa que puedan tener sus movimientos lo que más interesa. Si tenemos en cuenta, por ejemplo, que el Silencioso es un personaje que no pronuncia ni una palabra a lo largo de la obra, que se le describa "con las piernas cruzadas con displicencia, desvencijado en un sillón" y siempre en escena en el mismo lugar, nos puede dar cuenta de la importancia de estas acotaciones. En el mismo caso están otra sombra y "un ser exagüe y desmayado", ambos están así siempre en escena y sólo se remueven cuando oyen algo inquietante.

En cuanto al resto de los personajes que realmente se mueven, casi siempre lo hacen con "pasos menudos y lentos" "silenciosos", "sin sentirseles". Es interesante anotar que Ramón utiliza el recurso clásico del desfile de los personajes por escena; los movimientos de éstos al pasar tienen las características que hemos descrito.

Más importante es destacar que hay dos grupos de movimientos colectivos: uno es el de los nobles que entran en escena independientemente. No hay individualidad entre ellos, todos se saludan y comportan afectadamente, representan un grupo homogéneo cuyos movimientos lo son también -incluso la escenita autónoma sin palabras en la que el bufón zancadillea al marqués-. El otro movimiento de grupo es el corro que forman todos los personajes cuando deciden salir al jardín, el simbolismo del corro justifica su realización en escena y de eso hablaremos más adelante.

\section{Maquillaje-peinado-traje}

Aunque no tenemos referencias concretas a todos los personajes de la obra, aquellas que tenemos destacan por su oportunidad y su coherencia. Las tres mujeres muertas de la obra con personalidad diferenciada -y en cierta manera también las nobles- están descritas con cierto detalle. Gloria la Profesa, virgen, va toda vestida de blanco con una toca en la cabeza; Sara, blanca de tez y el pelo artificialmente blanco, lleva un vestido ajustado y zapatos de tacón. Frente a ellas, Leticia, la única mujer que tuvo una aventura 
-aunque luego le fuera fiel- va vestida de rojo, es rubia y lleva peinado de vuelo. La personalidad de estas tres mujeres ha quedado establecida por su aspecto externo. Tanto la ropa como la forma de llevar el pelo son significativos de lo que estas mujeres fueron y armonizan perfectamente con la caracterización que se les ha dado a través de los otros signos. En cuanto al resto de los personajes, el bufón también va de rojo con un gorro frente al grupo de nobles cuyos trajes son "fanfarrones, auríferos y prendidos de grandes cruces". Hay alguna descripción más, pero creo que estas son suficientes para dar una idea de cuál es el uso que hace Ramón de dichos elementos.

Tras analizar estos primeros signos podemos decir que la combinación de todos ellos produce una coherente interrelación entre los sistemas signicos auditivos y visuales que son, a fin de cuentas, los que caracterizan externamente al personaje y por tanto, a través de las cuales el espectador recoge información paralcla a la proporcionada por los signos lingüísticos.

\section{Accesorios-decorado}

El decorado está perfectamente descrito por Ramón en la primera acotación: se trata de un viejo salón lleno de objetos antiguos: retratos, un clavicordio, arcones, una armadura... La descripción es realmente detallada. En contraste con la acción que ocurre "en nuestros días" el lugar pertenece al pasado y denota decadencia y abandono, se trata de un palacio deshabitado pero que continúa estando habitado por sus muertos y su vieja parafernalia. De todos los elementos destaca "un tapiz flamenco en que dos arcadiantes se besan". Este tapiz, a medio camino entre decorado y accesorio, realiza un importante papel referencial: ahí está la carnalidad que todos desean.

Otros accesorios, esta vez procedentes de los personajes, son también significativos. Es el caso de los "cascabeles que no suenan", del bufón o de la espada del marqués. Los primeros sirven para hacer el efecto contrario a lo que estos objetos son: tristezasilencio. La segunda, objeto de burla por parte del bufón, caracteriza la cobardía de la clase noble.

El espacio escénico en el que se desarrolla la acción queda detalladamente descrito. Otra cuestión es qué hacer con la propuesta de espacio escénico externo: el jardín "se presiente otoñal, ciego, abandonado". A voluntad del director de escena el jardín estará o no, pero si lo está deberá ser tan decadente como el propio palacio en contraste con las esperanzas de los personajes.

\section{Iluminación}

Sólo dos indicaciones: "un amplio salón oscuro" en la primera acotación que no variará hasta la llegada de Rosa con "candil encendido" que se apaga inmediatamente con una ráfaga de viento al abrir el balcón. El jardín esta iluminado por blanco de luna. Está claro el juego de oposiciones vida/muerte, luz/oscuridad en el que por otra parte, se desarrolla la obra. 


\section{Música-sonido}

Hay una ausencia total de música y casi de cualquier ruido. La única alusión a cierto sonido es "se escuchan voces fuera", el resto de las referencias se dirijen a resaltar el silencio como único "sonido" posible. Un "silencio neumático" perfectamente coherente con la "muerte" que reina en escena.

Podríamos sacar algunas conclusiones generales de esta primera parte. La mayoría de los sitemas sígnicos forman grupos interrelacionados y dependientes de otros sistemas: así, por ejemplo, mímica, gesto y movimiento forman un todo que a la vez hace la doble función de caracterizar a los personajes y a la obra misma por la común exigencia de una especie de ralentización en todos los movimientos. Esta lentitud viene a encajar con la falta de acción que hemos comprobado al estudiar la palabra y el tono igualmente monónoto y sin estridencias que exige la dición; si recordamos ahora la parquedad de los ruidos y la ausencia de música resulta que los signos auditivos del actor y los auditivos de fuera del actor coinciden perfectamente para dar a la obra el clima que necesita. También los signos visuales de actor y escenario tienen que ver, aunque los primeros no estén enteramente desarrollados. El reparto simbólico de colores y trajes armoniza con la exuberancia decorativa, y el contraste de épocas se acentúa -a excepción de los nobles cuya indumentaria está tan pasada de moda como la propia decoración.

\section{DIMENSIÓN SEMÁNTICA}

Estamos de lleno en el campo de lo significativo. Estructuralmente, el primer productor de significación es el discurso de El hombre anónimo, alter-ego de Ramón en escena, que explica al público lo que va a ver:

"He aquí una historia lamentable y sin pundonor. Viene a deciros de la muerte, otra cosa de la que habíais concebido, y de la vida, cosas absurdas, pero a las que responderá algo en vosotros por entre el fárrago de ideas de necesidad y de conservadurismo que manifestáis aún los más iconoclastas/.../ pero el autor quiere que matéis la muerte en vosotros arrancándoos su carátula, que prohibáis los miscreres y déis rienda suelta a vuestro jolgorio, por más intempestivo y voraz que sea."

En efecto, El drama del palacio deshabitado está lleno de toda la rebeldía que llenaba aquellos años de la vida de Ramón. Frente a la sociedad burguesa-conservadora, Ramón ataca sus dos puntos débiles: el social y el moral. El procedimiento que utiliza para ello es la presentación de un espacio simbólico en el que los personajes encarnan ideas, formas de entender el mundo en cualquier caso fracasadas. El contraste muertevida, pasado-presente, interior-exterior es en definitiva siempre la misma oposición entre lo que fue y lo que debió ser, entre la sociedad burguesa y un nuevo orden social, entre el instinto y la represión.

Dentro de este espacio cerrado -que es el escenario- se desarrolla la historia de un 
grupo de hombres y mujeres que, pertenecientes a estratos privilegiados de la sociedad, se lamentan ahora que están muertos de todo aquello que debían haber hecho en vida. Lo único que les queda es conversar infinitamente sobre ello, escuchar sus propias lamentaciones y, tal vez, tomar la decisión de abandonar el palacio y "meteorizarse" en el jardín -espacio de esperanza que se abre ante ellos, pero al que temen-. Los reproches que estos personajes se hacen a sí mismos están en su mayor parte referidos a la moralsexual: Gloria la Profesa: "!Por qué grité aquella noche! !Por qué llamé a la tornera!"; el ayuda de camara: "Y me sonrió la marquesa. ¿Por qué no pagué su sonrisa?"; Leticia: "¿No podrá ser ya?". Otros hacen referencia a cierta repulsa de clase: Sara: "!Porqué fuera mi palefrenero!...Vanos repulsos"; el ayuda de cámara:" ¿Por qué no robé aquello? ¿Por qué fui tan servil?". Y algunos, los del bufón, centran sus quejas en denunciar la injusticia social: El Bufón: “!Quizá hay Marqueses aún!...!Pobres de ellos si pudieran irrumpir en la vida los de la fosa común..."

El no ser de todos estos personajes contrasta con el ser vital de Rosa y Juan. Rosa: "!No sé qué voluntad me ha dado por ti esta noche!"; Juan: "Y a mi por ti, rapaza". En ellos no hay denuncia ni lamentación: ellos hacen lo que sienten y esa parece ser la propuesta de Ramón. Un estudio más detallado de personajes y símbolos nos despejará definitivamente todas las incógnitas.

\section{Personajes}

No ha tratado Ramón de hacer una tipología completa de personajes, un desfile por el que cada clase y status tenga su representante; ha habido una selección en base al motivo de la denuncia y se ha centrado en aquellos sectores de la sociedad a los que ésta iba especialmente dirigida. Tenemos así un primer grupo de alta nobleza anticuada, ridícula e inmoral, cuya principal fuente de caracterización son los rasgos externos que cuadran perfectamente con el uso de un vocabulario arcaico que se materializa en expresiones como "bribón", "barragan", "insolente". Ellos probablemente no se reprimieron, pero aparentaron hacerlo y obligaron al resto de la sociedad; es un grupo cerrado que utiliza un código particular y que en la obra ocupa un espacio cerrado al margen de los otros personajes. No tienen nombre propio: son el marqués, la marquesa, el conde y la condesa, lo que acentúa aún más su impersonalidad.

En contraste con ellos está el bufón, irreverente, deslenguado y oportunista; se aprovechó de la nobleza en su momento adulándola y divirtiéndola para conseguir beneficios y ahora se aprovecha de que nada le puede ocurrir para decirles lo que piensa. Sus críticas son duras y atacan la moral de clase. Se alegra del poder igualador de la muerte que le da la oportunidad de decir: "!Soy ya un desmandado!", pero continúa con ellos. D. Dámaso y D. Pedrín pertenecen a la baja nobleza, más de moda, más culta, más aburguesada. Son los más intelectuales, analizan la situación aunque finalmente ellos también se lamentan de lo que no hicieron. De D. Dámaso sabemos que mató a su mujer porque le intentaba ser infiel. Es el hombre español que defiende su honor, pero que cuando aparece una oportunidad -Rosa por ejemplo- no deja pasar la ocasión.

Diferente del resto -aunque a fin de cuentas ahí también- es el Silencioso, él hizo 
todo lo que los demás hubieran deseado, incluso murió sin confesor. Como el Bufón dice, a él no le aqueja la muerte, él al menos no tiene que estar mascullando su propio fracaso. "Es el más orondo de todos.. No cree en las palabras".

En cuanto al grupo de las mujeres, representan tres tipos distintos: Gloria la Profesa es la virgen por vocación -aunque ahora ya no lo sienta así-. Retirada del mundo de la carne se da cuenta ahora de su gran error y busca alguien que le de un beso o que quiera mirar sus senos. Casi en oposición a Gloria está Leticia, la mujer de D. Dámaso, ella quiso a otro hombre, al Silencioso, pero nollegó a la cita porque su marido la mató antes. En cualquier caso dice "te fui fiel" y probablemente en eso radicó su error. Sara, hija de los nobles, guardó fidelidad a un novio cuyas cartas guarda entre barriles de sándalo y dejó pasar oportunidades de disfrutar del placer con otros hombres porque no eran de su clase.

Frente a este grupo de personajes muertos están los personajes vivos. Ellos encarnan al pueblo, son la frescura, la espontaneidad, el instinto, el placer. Rosa y Juan son el triunfo de la vida. Están caracterizados por sus actos y por sus palabras: "rapaza" " "mi Juanón" y no hacen sino agudizar la artificiosidad y la defunción real y vital de los otros personajes.

Es importante resaltar que muchos de los personajes no tienen nombre propio: $\mathrm{El}$ bastardo, el ayuda de cámara, los marqueses, los condes, el bufón; representan exactamente lo que sus nombres indican, están despersonalizados, hacen referencia a toda una clase -no necesariamente en el sentido social-. Sólo los personajes con más funcionalidad tienen un nombre: D. Dámaso, D. Pedrín, Sara, Leticia, Gloria la Profesa, Juan, Rosa. Ellos son todos los hombres y cualquier hombre y sus nombres no necesitan tener un valor simbólico especial, el diálogo es suficiente para identificarlos.

Tampoco hay que olvidar el grupo de sombras y daguerrotipos que pululan por la escena. No son nada ni nadie, sólo contribuyen a acentuar el ambiente decrépito del lugar y su actuación es de pura comparsa y de dependencia con respecto a los personajes principales.

\section{Símbolos}

Con la interpretación simbólica, El drama del palacio deshabitado cobra definitivamente sentido. Los símbolos vida/muerte son los más importantes de la obra. Los personajes ahora están muertos, pero también lo estaban simbólicamente durante su existencia en el mundo real.

Son los representantes de unas clases muertas, de una ideología muerta, de una moral muerta. Son los representantes de la represión que mata los instintos; son la pasividad, la inercia, las víctimas y a la vez los creadores de las convenciones sociales que comprimen la vida del hombre. Los personajes vivos, por el contrario, representan la vida en su forma más pura. Es el triunfo de los instintos, de la pureza de sentimientos, del pueblo llano que desconoce los sistemas morales inventados por las clases sociales que sustentan el poder.

Creo que ese es el verdadero sentido que hay que darle a la oposición vivo-muerto 
en esta obra. Ramón nos está mostrando el contraste ante nuestros ojos de un mundo auténtico frente a un mundo corrompido por los sistemas de represión del individuo. Me parece que no hay duda sobre cuál es su opción.

Además de este símbolo-eje hay otro en estrecha relación con el primero: la habitación cerrada frente al Sol-Jardín, espacio escénico sugerido pero ausente del escenario. Los personajes muertos se mueven dentro del espacio agobiante de la habitación cerrada, con ventanas cerradas en la penumbra, reconcentrados en sus miserias. Los personajes vivos vienen de fuera, traen la luz y "corrompen" el espacio que habitan los muertos haciendo allí el amor. Pero para los muertos son el Sol y el Jardín los símbolos de la liberación, ellos están condenados a su habitación, temerosos de perder sus recuerdos -como dice en un momento D. Pedrín-. El jardín es el camino hacia la integración en la naturaleza, la absorción definitiva por el mundo, la comunión total con la creación: "A veces nos tenemos que dar cuenta de que no somos el rayo de luna, ni la ráfaga de viento, ni un mojón de tierra castellana, ni un retal de musgo" El Solpurificador, el Jardín-liberación funcionarán durante toda la obra contrastivamente, como posibilidad casi innombrable a la que sólo D. Dámaso y Leticia se lanzarán al final estimulados por la presencia de la pareja Rosa-Juan.

A la luz de los símbolos, El drama del palacio deshabitado se clarifica y podemos reconocerlo como un intento de Ramón Gómez de la Serna por aportar algo a la alicaída escena española de la época. Aunque nunca fue estrenada, forma parte de un corpus de obras que son testimonio de una inquietud que Ramón, hombre de su tiempo donde los haya, compartía.

Partiendo desde sus preocupaciones más íntimas, desde la motivación más personal, Ramón hace extensiva su queja al resto de la sociedad y nos ofrece así un testimonio de rebeldía erótico-moral y social insólito en nuestra literatura.

\section{Bibliografía}

- Camón Aznar, José. [1972] Ramón Gómez de la Serna en sus obras, Madrid, Espasa Calpe.

- Cardona, Rodolfo. [1957] Ramón, New York, Eliseo Torres and sons.

- Díez Borque, José Ma . [1988] Historia del teatro en España, II, Madrid, Taurus.

- Dougherty, Dru. "Talia convulsa: la crisis teatral de los años veinte" en Lima, L. y Dougherty, Dru. [1984] Dos ensayos sobre el teatro español de los veinte, Murcia, Universidad de Murcia, pp. 87-155.

- Gómez de la Serna, Ramón. [s.a.] Obras Selectas, Madrid, Editorial Plenitud.

- Gómez de la Serna, Ramón. [1956] Obras completas t.I, Barcelona, Editorial AHR.

- Granjel, Luis. [1963] Retrato de Ramón, Madrid, Guadarrama.

- Kowzan, Tadeus. "El signo en el teatro. Introducción a la semiología del arte como espectáculo" en Adorno y otros, [1969] El teatro y su crisis actual, Caracas, Monte Avila Editores, pp. 25-60.

- Mazzati Garciol, Rita. [1974] Ramón Gómez de la Serna, New York, Twayne Publishers. 
- Palenque, Marta. [1992] El Teatro de Gómez de la Serna; estética de una crisis, Sevilla, Alfar.

- Ponce, Fernando. [1968] Ramón Gómez de la Serna, Madrid, Unión Editorial.

- Rubio Jiménez, Jesús. [1982] Ideología y teatro en España: 1890-1900, Zaragoza, Dept. de Literatura española. Universidad de Zaragoza.

- Ruiz Ramón, Francisco. [1975] Historia del Teatro Español. Siglo XX, Madrid, Cátedra.

- Tordera, Antonio. "Teoría y técnica del análisis teatral" en J. Talens ed. [1978] Elementos para una semiótica del texto artístico, Madrid, pp. 157-199,

- Umbral, Francisco. [1978] Ramón y las vanguardias, Madrid, Espasa-Calpe. 